\title{
Erratum to: Ronald D. Siegel: Integrating Mindfulness into Counseling and Psychotherapy, and Shirin Shoai: Instructor's Manual. Psychotherapy.net, Mill Valley, CA, USA, 2015, 3hrs 11 mins Running Time
}

\author{
Ramasamy Manikam ${ }^{1}$
}

Published online: 22 April 2016

(C) Springer Science+Business Media New York 2016

Erratum to: Mindfulness (2016) 7:570-572

DOI 10.1007/s12671-015-0488-2

In the original published version of this article the name "Shalom" appears incorrectly in three instances on page \#571. The correct name should have appeared as "Yalom".

The online version of the original article can be found at http://dx.doi.org/ 10.1007/s12671-015-0488-2.

Ramasamy Manikam

ramasamy@verizon.net

113 Strongwood Rd, Owings Mill, MD 21117, USA 